\title{
Feasibility of using death certificates for studying place of death in Latin America
}

\author{
Katja Seitz, ${ }^{1}$ Luc Deliens, ${ }^{2}$ Joachim Cohen, ${ }^{2}$ Emanuel Adrian Cardozo, ${ }^{3}$ Vilma A. Tripodoro, ${ }^{4}$ \\ Fernando Cesar Iwamoto Marcucci, ${ }^{5}$ Luís Fernando Rodrigues, ${ }^{6}$ Lea Derio, ${ }^{7}$ Miguel Antonio \\ Sánchez-Cárdenas, ${ }^{8}$ Valentina Salazar, ${ }^{9}$ Victor Rolando Samayoa, ${ }^{10}$ Ximena Pozo, ${ }^{11}$ Diane A. \\ Dykeman-Sabado, ${ }^{12}$ Celina Castañeda de la Lanza, ${ }^{13}$ Nineth Carolina Baltodano Algaba, ${ }^{14}$ \\ Gabriela Píriz Alvarez, ${ }^{15}$ Leticia Viana, ${ }^{16}$ Tulio González ${ }^{17}$ and Tania Pastrana ${ }^{1}$
}

Suggested citation Seitz K, Deliens L, Cohen J, Cardozo EA, Tripodoro VA, Marcucci FCI, et al. Feasibility of using death certificates for studying place of death in Latin America. Rev Panam Salud Publica. 2021;45:e149. https://doi.org/10.26633/RPSP.2021.149

ABSTRACT Objective. This paper assesses the availability and quality of death certificate data in Latin America and the feasibility of using these data to study place of death and associated factors.

Methods. In this comparative study, we collected examples of current official death certificates and digital data files containing information about all deaths that occurred during 1 year in 19 Latin American countries. Data were collected from June 2019 to May 2020. The records for place of death and associated variables were studied. The criteria for data quality were completeness, number of ill-defined causes of death and timeliness.

Results. All 19 countries provided copies of current official death certificates and 18 of these registered the place of death. Distinguishing among hospital or other health care institution, home and other was possible for all countries. Digital data files with death certificate data were available from 12 countries and 1 region. Three countries had data considered to be of high quality and seven had data considered to be of medium quality. Categories for place of death and most of the predetermined factors possibly associated with place of death were included in the data files.

Conclusions. The quality of data sets was rated medium to high in 10 countries. Hence, death certificate data make it feasible to conduct an international comparative study on place of death and the associated factors in Latin America.

Keywords $\quad$ Death certificates; comparative study; Latin America.

1 Department of Palliative Medicine, Medical Faculty, RWTH Aachen University, Aachen, Germany $₫$ Tania Pastrana, tpastrana@ukaachen.de

2 End-of-Life Care Research Group, Vrije Universiteit Brussel and Ghent University, Brussels, Belgium

3 National Ministry of Health, Buenos Aires, Argentina

4 Department of Palliative Care, Institute of Medical Research A. Lanari, University of Buenos Aires, Buenos Aires, Argentina

5 Hospital Dr. Anísio Figueiredo, State Health Secretariat of Paraná, Londrina, Brazil

6 Palliative Care Unit, Barretos Cancer Hospital, Barretos, Brazil

7 Nursing Department, Faculty of Medicine, University of Chile, Santiago, Chile

8 ATLANTES Global Palliative Care Observatory, Institute for Culture and Society, University of Navarra, Pamplona, Spain

\footnotetext{
9 Faculty of Health Sciences, University of Tolima, Ibague, Colombia

10 Palliative Care Unit, Institute of Cancerology, Guatemala City, Guatemala

11 Palliative Care Unit, Hospital Comprehensive Care for the Elderly, Ministry of Public Health, Quito, Ecuador

12 Foundation Corazon del Siervo, Santo Domingo, Dominican Republic

13 Coordination for Advance Directives and Palliative Care Program, Institute of Health of the State of Mexico, Ministry of Health of Mexico, Toluca, Mexico

14 Oncology Center for Chemotherapy and Palliative Care, Ministry of Health, Managua, Nicaragua

15 Faculty of Medicine, University of the Republic, Montevideo, Uruguay

16 Department of Palliative Care and Pain, National Cancer Institute, Capiata, Paraguay

17 Institute of Oncology Dr. Luis Razetti, Caracas, Venezuela
} 
Knowing where people die is crucial for health care planning and for enabling patients to receive adequate care at their preferred place of death $(1,2)$. Due to the epidemiological and demographic transitions in Latin America that are leading to more people with chronic illness, an increasing need for endof-life care is expected (3). In order to establish functioning care services and ensure they are available, it is necessary to identify locations where services and resources should be assigned (1). In addition to the benefits for patients and their caregivers, improving services for end-of-life care can provide economic advantages for the system (4). However, in Latin America only nine studies on the place of death have taken place: five in Mexico $(5-9)$, two in Brazil $(10,11)$ and two in Chile $(12,13)$. None of these studies included the entire population of a country or compared results to other countries in the region.

Vital statistics can provide answers to the questions of when, where and how people die. Ideally, they derive from data collected by civil registration, such as death certificates (14). Well-maintained data drawn from civil registrations are a comprehensive and reliable resource for research and development of health care services $(15,16)$. Several approaches have been used for evaluating the quality and availability of vital statistics, civil registration systems and death certificate data in Europe and globally (17-21). Previous studies in Europe have shown the value of using death certificates for studying place of death (17).

In this paper, we assess the availability and the quality of death certificate data for 1 year in 19 Latin American countries and the feasibility of using these data to study place of death and associated factors.

\section{METHODS}

\section{Study design}

In this first comparative study of the feasibility of using data from death certificates to study the place of death, we collected examples of current official death certificates and digital data files containing information about all deaths for the most recent year available in 19 Latin American countries: Argentina, Bolivia (Plurinational State of), Brazil, Chile, Colombia, Costa Rica, Cuba, Dominican Republic, Ecuador, El Salvador, Guatemala, Honduras, Mexico, Nicaragua, Panama, Paraguay, Peru, Uruguay and Venezuela (Bolivarian Republic of). The data were collected from June 2019 to May 2020.

A common database was created from the data files. Variables such as place of death, cause of death and other sociodemographic variables identified as relevant in the literature $(17,22$, 23) were extracted (Table 1).

\section{Availability of data}

To obtain the data, at least one research partner in every country was contacted and formally invited to collaborate on the project. Selection criteria for research partners were: (i) having expertise in conducting research, (ii) having access to the national information system and (iii) having experience with collaboration. The research partners are coauthors of this paper.

Research partners were asked to send a copy of the death certificate used in their country and to complete a questionnaire
TABLE 1. Information from data files about deaths in 19 Latin American countries included in the database

\begin{tabular}{ll}
\multicolumn{1}{c}{ Characteristic } & \multicolumn{1}{c}{ Description } \\
$\begin{array}{ll}\text { Year of registration or death } \\
\text { Study population }\end{array}$ & Most recent year available \\
& All deaths in the country or region \\
& Place of death (hospital, home, other health \\
care institution, other) & Cause of death (ICD code) \\
& Age \\
Variables & Sex \\
& Civil status \\
& Level of education \\
& Municipality of death \\
& Municipality of residence \\
& Urban or rural area \\
\hline $\begin{array}{l}\text { ICD: International Statistical Classification of Diseases and Related Health Problems. } \\
\text { aEither the year of death or year of registration was used depending on the country. } \\
\text { Source: Table prepared by the authors. }\end{array}$
\end{tabular}

about the data files available and the prerequisites for obtaining them.

Countries that submitted a copy of the official death certificate and/or a data file derived from death certificate data (with place of death information) were included.

\section{Feasibility of using data}

The data files and death certificates from each country were reviewed. To evaluate the feasibility of studying place of death and associated factors, the content and quality were analyzed, considering the following characteristics: (i) the content of the data, including the most recent year for which data were available, the total number of deaths in the data file, information on place of death and the availability of information about other variables possibly associated with place of death; and (ii) the quality of the data, which was assessed through indicators including completeness - that is, aiming for $100 \%$ registration, with the rate of mortality underregistration provided by the Pan American Health Organization (PAHO) (24) - and the quality and timeliness of reporting.

No indicator to estimate the quality of reporting of place of death was identified, so we used the indirect indicator of "quality of cause of death," described by Mathers et al. (18). This method classifies the data as being of high, medium or low quality based on the proportion of ill-defined codes (that is, underlying causes of death that give nonspecific information and lack diagnostic meaning, modified from Mathers et al.) (18) and the percentage of completeness $(18,20,21)$. Those records that were more than $90 \%$ complete and had a percentage of ill-defined causes of death below 10\% were considered to be of high quality, those with completeness between $70 \%$ and $90 \%$ or with the percentage of ill-defined causes of death between $10 \%$ and $20 \%$ were categorized as medium quality, and those with completeness below $70 \%$ or with the percentage of ill-defined codes above $20 \%$ were classified as low quality (18).

Timeliness was evaluated according to the World Health Organization's (WHO's) assessment tool (21), which rates registration systems as being highly adequate when data take less than 3 years to be published. A duration of 3 years is considered adequate. 


\section{Statement of ethical approval}

The project was approved by the ethics committee of RWTH Aachen University (approval no. EK 206/19); no additional approvals were needed from local ethics committees in Latin America. The data collected were completely anonymous, so no personal identification was possible.

\section{RESULTS}

\section{Availability of death certificates}

Altogether 19 countries provided a copy of their official death certificate (Table 2). In Argentina, every province has its own death certificate. For our study, we obtained the one used in Buenos Aires City. We excluded Bolivia (Plurinational State of) from the analysis because the place of death is registered only in cases of nonnatural death.

\section{Availability of data files}

Digital data files with death certificate data including information about the place of death were obtained from 12 countries
(Argentina, Brazil, Chile, Colombia, Costa Rica, Ecuador, El Salvador, Guatemala, Mexico, Paraguay, Peru and Uruguay) and one region (Caracas, Bolivarian Republic of Venezuela). No data files were provided by Cuba, the Dominican Republic, Honduras, Nicaragua and Panama (Table 2).

The procedure for obtaining the data files varied. Data files from Chile, Colombia, Ecuador and Mexico were publicly accessible on the homepage of the institution in charge (25-29) and came with corresponding dictionaries for the names of the variables and information about the codes used in the file. Data files and dictionaries were submitted by the research partners for Argentina, Brazil, El Salvador, Guatemala, Paraguay, Uruguay and Venezuela (Bolivarian Republic of).

In Costa Rica (30), Peru and Uruguay, it was necessary to make additional official requests. No fees had to be paid in any of the countries to obtain the data. The process of obtaining the data files took between 3 weeks (Paraguay) and 12 months (Peru).

\section{Feasibility of studying place of death}

Most recent year available and total number of deaths. At the time of data collection, data files were available from three countries for 2016, from eight countries for 2017 and from one country

TABLE 2. Availability of death certificates and data files in 19 Latin American countries, by country

\begin{tabular}{|c|c|c|c|c|c|c|}
\hline Country & Data availability & $\begin{array}{c}\text { Most recent } \\
\text { year of death } \\
\text { or registration } \\
\text { available in data } \\
\text { file }^{\text {a }}\end{array}$ & $\begin{array}{l}\text { Total number of } \\
\text { deaths in data file }\end{array}$ & Total population & Death rate ${ }^{c}$ & Comments \\
\hline Argentina & $\begin{array}{l}\text { Death certificate (Buenos Aires } \\
\text { City) and data file }\end{array}$ & 2017 & 341688 & 44044811 & 0.78 & $\begin{array}{l}\text { Via research partner; death certificate } \\
\text { different for every region }\end{array}$ \\
\hline $\begin{array}{l}\text { Bolivia (Plurinational } \\
\text { State of) }\end{array}$ & Death certificate & NA & NA & NA & NA & $\begin{array}{l}\text { No place of death reported on death } \\
\text { certificate }\end{array}$ \\
\hline Brazil & Death certificate and data file & 2017 & 1312663 & 207833831 & 0.63 & Via research partner \\
\hline Chile & Death certificate and data file & 2016 & 104026 & 18209068 & 0.57 & $\begin{array}{l}\text { Online; death certificate via research } \\
\text { partner }\end{array}$ \\
\hline Colombia & Death certificate and data file & 2017 & 227624 & 48909844 & 0.47 & $\begin{array}{l}\text { Online; individual data on age were } \\
\text { requested separately }\end{array}$ \\
\hline Costa Rica & Death certificate and data file & 2016 & 22601 & 4899345 & 0.46 & $\begin{array}{l}\text { Online, after registration; dictionary via } \\
\text { research partner }\end{array}$ \\
\hline Cuba & Death certificate & NA & NA & NA & NA & Via research partner \\
\hline Ecuador & Death certificate and data file & 2017 & 70841 & 16785361 & 0.42 & Online \\
\hline El Salvador & Death certificate and data file & 2017 & 39602 & 6388122 & 0.62 & Via research partner \\
\hline Guatemala & Death certificate and data file & 2017 & 81726 & 16087418 & 0.51 & Via research partner \\
\hline Honduras & Death certificate & NA & NA & NA & NA & $\begin{array}{l}\text { Via research partner; data not digitized, } \\
\text { according to research partner }\end{array}$ \\
\hline Mexico & Death certificate and data file & 2017 & 703047 & 124777324 & 0.56 & Online \\
\hline Nicaragua & Death certificate & NA & NA & NA & NA & Via research partner \\
\hline Panama & Death certificate & NA & $\mathrm{NA}$ & NA & NA & Via research partner \\
\hline Paraguay & Death certificate and data file & 2017 & 29021 & 6867062 & 0.42 & Via research partner \\
\hline Peru & Death certificate and data file & 2017 & 121142 & 31444297 & 0.39 & $\begin{array}{l}\text { Via official request and research } \\
\text { partner }\end{array}$ \\
\hline Dominican Republic & Death certificate & NA & NA & NA & NA & Via research partner \\
\hline Uruguay & Death certificate and data file & 2018 & 34128 & 3449299 & 0.99 & Via research partner \\
\hline $\begin{array}{l}\text { Venezuela (Bolivarian } \\
\text { Republic of) }\end{array}$ & $\begin{array}{l}\text { Death certificate and data file } \\
\text { (Caracas region) }\end{array}$ & 2016 & 18590 & No data & NA & Via research partner \\
\hline
\end{tabular}

NA: not available.

aThe year of registration was available for Brazil, Chile, Colombia, Paraguay and Venezuela (Bolivarian Republic of); the year of death was available for Argentina, Costa Rica, Ecuador, El Salvador, Guatemala, Mexico, Peru and Uruguay. "This category refers to the total population of the country or region during the reference year for the data file.

cThis is the number of registered deaths in the data file divided by the total population.

Source: Table prepared by the authors from their data, with the exception of the total population, for which the source was reference 36 
for 2018 (Table 2). The total number of deaths in the population ranged from 22601 in Costa Rica to 1312663 in Brazil, excluding stillbirths. In the region of Caracas, Venezuela (Bolivarian Republic of), the total number of deaths was 18590 (Table 2).

Place of death information on death certificates and in data files. In every country, death at home was included on the death certificate and a distinction could be made between death at a hospital or other health care institution and at home or other (Table 3). Distinguishing between hospital and other health care institution was possible only in eight countries.

In Argentina, Costa Rica, Dominican Republic, Ecuador, Honduras, Mexico, Nicaragua, Paraguay and Peru, the category "hospital" was not available on the death certificate. For example, in Costa Rica and Panama, the place of death was written rather than coded, so categories could be added to the database created for this study. In Argentina, Ecuador, Mexico, Paraguay and Peru, the health care provider was reported. In Latin America, different providers operate their own facilities within the health care system. Because most providers operate only hospitals, these facilities were recoded into the category "hospital" in our database.

The categories "workplace" ( 4 countries) and "public place" (10 countries) are also common on death certificates (Table 3 ).

In most countries, the categories for place of death in the data files were identical to the categories on the death certificates. In Costa Rica, the data file contained more categories than the death certificate because written text was recoded. In Ecuador, the categories in the data file were slightly different from those on the death certificate.

The rate of deaths registered in the data file without information about the place of death was highest in Peru at $25.5 \%$, and it was between $0.0 \%$ and $5.8 \%$ in the other countries, but in the region of Caracas it was $7.1 \%$ (Table 3 ).

Variables potentially associated with place of death. Sociodemographic variables were available from all countries (Table 4). Age, sex and civil status (single, married, widowed, divorced, separated, civil partnership) were available from every country except for Colombia (where online data provided age only in aggregated form) and Argentina (where civil status was not available). The level of education was provided from every country except Costa Rica and El Salvador. Categories, however, were inconsistent between the countries due to different educational systems.

With the exceptions of Chile, Costa Rica and Ecuador, the location of death and place of residence were available with the precision of what in an international context would correspond to municipality. Zip codes are not commonly used in Latin America.

Chile, Colombia, Costa Rica, Ecuador, Guatemala, Mexico and Venezuela (Bolivarian Republic of) provided information about whether the place of death or residence, or both, could be classified as rural or urban. In Brazil, this information could be gained through linkage to an external file, and in El Salvador through the location of the place of death or residence.

TABLE 3. Categories for place of death recorded on death certificates and in data files in 18 countries in Latin America, by country

\begin{tabular}{|c|c|c|c|c|c|c|}
\hline \multirow[t]{2}{*}{ Country or region ${ }^{\mathrm{a}}$} & \multicolumn{5}{|c|}{ Place of death } & \multirow{2}{*}{$\begin{array}{l}\text { Percentage of data files } \\
\text { missing information } \\
\text { about place of death }\end{array}$} \\
\hline & Hospital & $\begin{array}{l}\text { Other health care } \\
\text { institution }\end{array}$ & Home & Public place & Other & \\
\hline \multicolumn{7}{|c|}{ Both death certificate and data file available } \\
\hline Argentina & Institutions combined & Institutions combined & Yes & NA & $Y_{e s}^{b}$ & 1.3 \\
\hline Brazil & Yes & Yes & Yes & Yes & Yes & 0.1 \\
\hline Chile & Yes & NA & Yes & NA & Yes & 0.0 \\
\hline Colombia & Yes & Yes & Yes & Yes & Yes, workplace & 0.7 \\
\hline Costa Rica & Text onlyc & Text onlyc & Yes & Yes & Only from data file & 0.3 \\
\hline Ecuador & Institutions combined & Institutions combined & Yes & NA & Yes & 0.0 \\
\hline El Salvador & Yes & Yes & Yes & Yes & Yes & 0.0 \\
\hline Guatemala & Yes & Yes & Yes & Yes & Yes, workplace & 5.8 \\
\hline Mexico & Institutions combined & Institutions combined & Yes & Yes & Yes & 2.2 \\
\hline Paraguay & Institutions combined & Institutions combined & Yes & Yes & Yes & 0.0 \\
\hline Peru & Institutions combined & Institutions combined & Yes & Yes & Yes, workplace & 25.5 \\
\hline Uruguay & Yes & Yes & Yes & Yes & Yes & 0.1 \\
\hline $\begin{array}{l}\text { Venezuela (Bolivarian } \\
\text { Republic of; Caracas region) }\end{array}$ & Yes & Only from data file & Yes & Yes & $\begin{array}{l}\text { Only from data file, } \\
\text { workplace }\end{array}$ & 7.1 \\
\hline \multicolumn{7}{|c|}{ Only death certificate available } \\
\hline Cuba & Yes & Yes & Yes & NA & Yes & \\
\hline Dominican Republic & Institutions combined & Institutions combined & Yes & Yes & Yes & \\
\hline Honduras & Institutions combined & Institutions combined & Yes & NA & Yes & \\
\hline Nicaragua & Institutions combined & Institutions combined & Yes & NA & Yes & \\
\hline Panama & Text only & Text only & Text only & Text only & Text only & \\
\hline
\end{tabular}

NA: Not available

a Bolivia was excluded from the analysis because place of death is registered only for nonnatural deaths.

${ }^{6}$ This category includes residential care for elderly people.

c Includes one category for each institution or hospital.

Source: Table prepared by the authors from their data. 
TABLE 4. Availability of variables possibly associated with place of death in data files for 13 countries in Latin America, by variable

\begin{tabular}{|c|c|c|c|c|c|c|c|c|c|c|c|c|}
\hline \multirow[t]{2}{*}{ Variable } & \multicolumn{12}{|c|}{ Country } \\
\hline & Argentina & Brazil & Chile & Colombia & $\begin{array}{c}\text { Costa } \\
\text { Rica }\end{array}$ & Ecuador El Salvador & Guatemala & Mexico & Paraguay & Peru & Uruguay & $\begin{array}{l}\text { Venezuela } \\
\text { (Bolivarian } \\
\text { Republic of) }\end{array}$ \\
\hline
\end{tabular}

\section{Sociodemographic variables}

\begin{tabular}{|c|c|c|c|c|c|c|c|c|c|c|c|c|c|}
\hline Age & $x$ & $x$ & $X$ & $X^{a}$ & $X$ & $x$ & $X^{b}$ & $x$ & $x$ & $X$ & $x$ & $X$ & $X$ \\
\hline Sex & $X$ & $X$ & $X$ & $X$ & $X$ & $x$ & $x$ & $x$ & $X$ & $X$ & $X$ & $X$ & $X$ \\
\hline Civil status & & $X$ & $X$ & $X$ & $X$ & $x$ & $x$ & $x$ & $X$ & $X$ & $X$ & $X$ & $X$ \\
\hline Level of education & $X$ & $x$ & $X$ & $X$ & & $x$ & & $x$ & $x$ & $X$ & $X$ & $X$ & $X$ \\
\hline \multicolumn{14}{|l|}{ Clinical characteristics } \\
\hline $\begin{array}{l}\text { Cause of death, including } \\
\text { ICD-10 code }\end{array}$ & $x$ & $x$ & $x$ & $x$ & $X$ & $x$ & $x$ & $X$ & $x$ & $x$ & $X$ & $X$ & $X^{c}$ \\
\hline \multicolumn{14}{|c|}{ Residence characteristics } \\
\hline Municipality of death & $x$ & $x$ & & $X$ & $x$ & $x$ & $x$ & $x$ & $x$ & $X$ & $x$ & $X$ & $X$ \\
\hline Municipality of residence & $X$ & $X$ & $X$ & $X$ & $X$ & $X^{d}$ & $X$ & $X$ & $X$ & $X$ & $X$ & $X$ & $X$ \\
\hline $\begin{array}{l}\text { Urban or rural place of } \\
\text { death }\end{array}$ & & $X^{e}$ & & $X$ & & $x$ & $X^{f}$ & $x$ & & & & $X^{c}$ & \\
\hline Urban or rural residence & & $X^{e}$ & $X$ & $X$ & $X$ & $x$ & $X^{\dagger}$ & & $X$ & & & $X^{c}$ & \\
\hline
\end{tabular}

X: data available.

Available only up to age 99.

Missing in more than $50 \%$ of cases.

Avaliable only for the province, not the municipality.

Avaliable through linkage to an external file.

Source: Table prepared by the authors from their data.

All countries use the International Statistical Classification of Diseases and Related Health Problems, 10th edition, (ICD-10) to code the underlying cause of death.

\section{Quality assessment}

Completeness of registration. Completeness of mortality registration ranged from 54\% in Peru to 100\% in Argentina, Mexico and Uruguay (Table 5).

Quality of reporting. The proportion of ill-defined codes ranged from 3.8\% in Mexico to 30\% in El Salvador. In every country, an ICD-10 code was registered for all deaths, except for Caracas, Bolivarian Republic of Venezuela, where cause of death information was missing in $54.6 \%$ of deaths in the data file. To avoid distorting the rate of ill-defined codes in relation to all cause of death codes, we added cases with missing cause of death information to the category of ill-defined codes. The databases obtained in this study are considered to be of medium quality (Table 5).

Timeliness. Timeliness was considered to be highly adequate for the 13 countries that provided a digital data file, according to the WHO assessment tool (21). Since we received the data in 2019-2020 and the data files refer to the years 2016 (received in 2019), 2017 and 2018 (received in 2019 and 2020), the time from data collection to data publication is less than 3 years for all countries.

\section{DISCUSSION}

All 19 Latin American countries included in this study provided examples of their death certificates: 18 registered the place of death on the certificate and 13 provided a digital data
TABLE 5. Quality assessment of data files for death certificates from 13 countries in Latin America, by country

\begin{tabular}{lcccl} 
Country & $\begin{array}{c}\text { Completeness } \\
\text { of mortality } \\
\text { registration }{ }^{\mathrm{a}}(\%)\end{array}$ & $\begin{array}{c}\text { III-defined } \\
\text { codes }^{\mathrm{b}}(\%)\end{array}$ & $\begin{array}{c}\text { Timeliness of } \\
\text { reporting }\end{array}$ & $\begin{array}{c}\text { Quality of } \\
\text { data }\end{array}$ \\
Argentina & 100 & 16.3 & Highly adequate & Medium \\
Brazil & 98 & 9.5 & Highly adequate & High \\
Chile & 93 & 5.1 & Highly adequate & High \\
Colombia & 78 & 4.5 & Highly adequate & Medium \\
Costa Rica & 86 & 5.6 & Highly adequate & Medium \\
Ecuador & 80 & 10.4 & Highly adequate & Medium \\
El Salvador & 90 & 30.0 & Highly adequate & Low \\
Guatemala & 99 & 14.0 & Highly adequate & Medium \\
Mexico & 100 & 3.8 & Highly adequate & High \\
Paraguay & 85 & 7.9 & Highly adequate & Medium \\
Peru & 54 & 9.4 & Highly adequate & Low \\
Uruguay & 100 & 16.2 & Highly adequate & Medium \\
Venezuela & 89 & $66.1^{\text {d }}$ & Highly adequate & Low \\
(Bolivarian & & & & \\
Republic of; & & & & \\
Caracas region) & & & & \\
\hline
\end{tabular}

a Completeness of mortality registration was calculated for each country by subtracting from $100 \%$ the rate of mortality underreporting as provided by the Pan American Health Organization's online database for the health situation in the Americas (24). In each country, the rate for the most recent year available was used. ${ }^{b}$ This represents the number of deaths assigned to ill-defined codes or without cause of death information divided by the total number of deaths.

"Timeliness was assessed using the WHO assessment tool (21).

dCause of death information was missing for $54.6 \%$ of deaths.
Source: The table was prepared by the authors based on the results of their study, with the exception of the Source: The table was prepare
category for completeness.

file. None of the data were older than 3 years. For all countries, it was possible to distinguish the place of death among a hospital or other health care institution, home and other. The data are considered to be of high quality for three countries, medium quality for seven countries and low quality for three 
countries. Different categories for the place of death, as well as most of the predetermined factors possibly associated with it, are available from the data files, making it feasible to conduct an international comparative study of the place of death in Latin America.

In general, rather than distinguishing between hospitals and other health care institutions (such as nursing homes or outpatient facilities), a distinction is more often made between private and public institutions (for example, in Argentina, Guatemala, Mexico, Panama, Peru and the Bolivarian Republic of Venezuela) or between different health care providers (for example, in Guatemala, Mexico, Paraguay, Peru). The structure of many health care systems is fragmented and decentralized in Latin America, meaning that they are made up of several main providers within the health care system, with each one operating its own facilities. The affiliation with a particular provider of a facility where the death occurred is primarily documented in the death certificate rather than whether the death occurred in a hospital or another type of facility.

\section{Availability of data}

Retrieving data files in Latin America was relatively straightforward. Although some were available online, most could be obtained within less than 4 months by contacting local research partners and payment was not required. The process seemed to be simpler in Latin America than in European countries, where fees have to be paid and additional approvals are required alongside those provided by the agencies responsible for death certification (17).

\section{Quality of data}

Information on the place of death and most of the sociodemographic variables possibly associated with the place of death were available in the data files.

According to our analysis, Brazil, Chile and Mexico provide mortality data of high quality, while data from Argentina, Colombia, Costa Rica, Ecuador, Guatemala, Paraguay and Uruguay are considered to be of medium quality and data from El Salvador, Peru and Caracas (Bolivarian Republic of Venezuela) were of low quality.

These 13 Latin American countries, including one region, have been included in other studies assessing the quality of global mortality data (18-20). Mathers and colleagues studied completeness and ill-defined codes and whether the most recent ICD version was used (18). Mathers et al. included data from 1990 to 2003, which were the most recent years with at least $50 \%$ completeness. They classified data provided by Mexico and the Bolivarian Republic of Venezuela as high quality; data from Ecuador, Paraguay and Peru as low quality; and data from the remaining countries as medium quality (Argentina, Brazil, Chile, Colombia, Costa Rica, El Salvador, Guatemala, Uruguay). European countries performed slightly better in their study. Of the European countries included, almost half were classified as providing medium-quality data, one third as providing high-quality data and less than one fifth as providing low-quality data (18).

In another study, a more comprehensive measure was used, and the average quality of data for the years 2005 to 2009 was analyzed (19). The quality of data was classified as very high in Chile, Costa Rica, Mexico and Venezuela (Bolivarian Republic of); as high in Argentina, Brazil, Colombia, El Salvador and Guatemala; and as medium in Ecuador, Paraguay, Peru and Uruguay.

Overall, these findings correspond well with our results, with the exception of El Salvador and the Bolivarian Republic of Venezuela, which performed more poorly in our analysis than in both studies mentioned above.

In 2014 a global comparison between seven regions across the globe (East Asia and the Pacific, Eastern Europe and Central Asia, high-income countries, Latin America and the Caribbean, North Africa and the Middle East, South Asia and sub-Saharan Africa), found that the region Latin America and the Caribbean scored second after high-income countries in terms of the quality of vital statistics; Chile, Costa Rica, Mexico and Venezuela (Bolivarian Republic of) stood out among developing countries because they scored highly, although the registration systems in developed countries generally performed better (20).

When adding and combining more indicators for data quality, such as internal consistency and quality of reporting on age and sex, cause of death coding is shown to be an important factor in the overall performance of the registration system (20). Accurate cause of death coding is a well-known indicator of the quality of coding (18), and it can give an idea of how precisely death certificates are completed. If cause of death information is poor, this may also apply to information about place of death on the certificate. When studying place of death in relation to cause of death, as we plan to do in the next step of this project, it is important that information about both the place of death and the cause of death is as accurate as possible.

\section{Improving the quality of vital statistics}

The majority of mortality data received were scored as being of medium quality. The study of the place of death can be useful for health care planning $(1,2)$, but the quality of the data needs to be strengthened and improved. The quality of vital statistics varies based on geographical and socioeconomic differences. Less affluent regions usually have worse coverage and worse quality data. These regions, due to a lack of access to health care, may also have a higher number of unregistered deaths and deaths occurring outside of hospitals, which may not be captured by our data. Cross-national comparisons are useful to identify the weaknesses in data quality in a country, but it is just as important to compare regions within a country to identify the areas with the greatest deficiencies where support for improvement is needed the most (31).

During the past 10 years, improving vital statistics has become a priority in public health (32). The relevance has already been highlighted by the Lancet in two series "Who counts?" (33) and "Counting births and deaths" (34). Implementing and maintaining well-functioning civil registration systems not only creates reliable sources for public health research but also creates sources for monitoring progress towards the United Nations Sustainable Development Goals and ensuring people's access to their legal rights (35).

\section{Opportunities for using the data}

Death certificate data have been found to be useful for public health research because they give the opportunity to study the 
place of death on a full-population basis rather than on limited samples (17). This provides information that can be used for improving policies at the country level.

More than 3 million deaths are documented in the combined whole-country digital data files available for the 12 countries in this study. This provides great statistical power for analyses deriving from the database, and it reflects a majority of Latin American countries. By comparing whole populations, information can be obtained about differences between health systems.

Since digital databases were easily accessible in many Latin American countries, they can be used to provide a time- and resource-saving way of collecting statistical data for research.

While the classification of place of death into private versus public institutions did not correspond to our model of classification (that is, hospital versus other health care institutions), it might provide a new dimension to investigate in future studies.

\section{Limitations of this study}

Some limitations of our study need to be taken into account. A more comprehensive assessment has been proposed in the Lancet Global Burden of Disease study (3). In this framework, the rate of ill-defined codes is combined with several other factors that indicate data quality, so that no reference point is given for the rate of ill-defined codes as a single indicator. In an earlier study, however, Mathers et al. (18) gave reference points for classifying the rates of ill-defined codes, which we chose to apply together with the set of ill-defined codes they provided.

Additionally, the rate of mortality underreporting published by PAHO does not refer to the same year as the data files we obtained (with the exception of data for Chile). Changes may have taken place in the time between PAHO's assessment and our analysis. In Peru, the PAHO measure was responsible for the classification of data as being low quality instead of medium quality. Because completeness ranged between 54\% and 100\%, not all deaths are represented in the data.

Since death certificates are completed by many people, the quality of the information can vary depending on their profession, education or how well they knew the deceased. Although we aim to estimate data quality, including the accuracy of coding, the process of completing the certificate, which our data is based upon, is difficult to verify in retrospect.

Across the 19 countries, coding for the place of death has been shown to be rather heterogeneous. This made it more challenging to fit place of death information into our categories through the reclassification or combination of categories, or both.

\section{CONCLUSIONS}

All 19 Latin-American countries included in this study provided death certificate forms. In 18 countries, the place of death is registered on the certificate. Digital files were available for 12 countries and one region. In these, a distinction can be made between the place of death categories "home," "hospital" or "other health care institution" and "other". The quality of the national data sets was rated as medium to high in 10 countries. Hence, data from death certificates provide a suitable and comprehensive resource with which to research place of death and associated factors in Latin America and enable comparisons of whole populations between and across countries.

As the next step in the project, we plan to produce a descriptive analysis of the common database created from the data obtained in this study. The database makes it possible to investigate place of death and its associated factors across Latin America and identify commonalities and specificities in patterns in different countries that will provide information for health policy and priorities for future research.

Authors' contributions. KS, TP and LD designed the study. All other coauthors contributed to data collection. KS analyzed the data and wrote the first draft. TP, LD and JC supervised the interpretation of the data. All authors revised the manuscript critically, approved the final version and are accountable for all aspects of the work.

Acknowledgements. The study was conducted in collaboration with the Global Palliative Care working group at the RWTH Aachen University, the End-of-Life Care Research Group, Vrije Universiteit Brussel and Ghent University, Ghent, Belgium, and the Palliative Care Association of Latin America.

The authors thank the following people for their support in accessing data or information from death certificates: Yaima Galán Alvarez (Departamento Registro Nacional de Cáncer de Cuba, Dirección Nacional de Registros Médicos y Estadística, Ministerio de Salud Pública de Cuba), Rolando Larin (Benjamin Bloom Children's Hospital, El Salvador), Roberto Castaneda (Departamento de Población, Gerencia de Estadísticas Sociales, El Salvador), Tulio Velázquez (Omega Foundation, Honduras), Gaspar Da Costa (Ministerio de Salud, Panama), Myrna McLaughlin-Anderson (University of Panama, Panama), Marco Bardales (Oficina General de Tecnologías de la Información, Ministerio de Salud, Peru), Ima León (Directora de Gestión de la Información, DIGESA, Ministerio de Salud, Uruguay).

The authors thank the following institutions for providing death certificate data: Departamento de Informática do Sistema Único de Saúde (DATASUS), Ministério da Saúde, Brazil; Departamento de Estadísticas e Información de Salud (DEIS), Chile; Archivo Nacional de Datos (ANDA) and Departamento Administrativo Nacional de Estadística (DANE), Colombia; Instituto Nacional de Estadística y Censos (INEC), Costa Rica; Instituto Nacional de Estadística y Censos (INEC), Ecuador; Instituto Nacional de Estadística y Geografía (INEGI), Mexico. The data file from Argentina comes from the "Informe estadístico de defunción (IED)" provided by Dr. Carlos Guevel, Director de Estadísticas e Información en Salud (DEIS) of the Ministerio de Salud de la Nación - Argentina (https://www.argentina.gob.ar/salud/ deis).

\section{Conflicts of interest. None declared.}

Funding. No funding was received in the course of this study.

Disclaimer. Authors hold sole responsibility for the views expressed in the manuscript, which may not necessarily reflect the opinion or policy of the Revista Panamericana de Salud Pública/Pan American Journal of Public Health or the Pan American Health Organization (PAHO). 


\section{REFERENCES}

1. Broad JB, Gott M, Kim H, Boyd M, Chen H, Connolly MJ. Where do people die? An international comparison of the percentage of deaths occurring in hospital and residential aged care settings in 45 populations, using published and available statistics. Int J Public Health. 2013;58(2):257-67.

2. Aguilar Huerta O, Bayón Cubero IC, Fernández Gutiérrez AL, Regadera González M. ¿La intervención de atención primaria influye en el lugar de fallecimiento de los pacientes en un programa de cuidados paliativos? [Does primary care intervention have an impact on the place of death for patients in a palliative care program?] Aten Primaria. 2021;53(8):102063. Spanish.

3. Sleeman KE, de Brito M, Etkind S, Nkhoma K, Guo P, Higginson IJ, et al. The escalating global burden of serious health-related suffering: projections to 2060 by world regions, age groups, and health conditions. Lancet Glob Health. 2019;7(7):e883-92.

4. Bergqvist J, Ljunggren G. The impact of integrated home palliative care services on resource use and place of death. J Palliat Med. 2020;23(1):67-73.

5. Cardenas-Turanzas M, Carrillo MT, Tovalin-Ahumada H, Elting L. Factors associated with place of death of cancer patients in the Mexico City Metropolitan area. Support Care Cancer. 2007;15(3):243-9.

6. Cardenas-Turanzas M, Torres-Vigil I, Tovalin-Ahumada H, Nates JL. Hospital versus home death: results from the Mexican Health and Aging Study. J Pain Symptom Manage. 2011;41(5):880-92.

7. Cardenas-Turanzas M, Tovalin-Ahumada H, Carrillo MT, Paez-Aguirre S, Elting L. The place of death of children with cancer in the metropolitan areas of Mexico. J Palliat Med. 2008;11(7):973-9.

8. Castillo-Guzman S, Palacios-Rios D, Nava-Obregon TA, Torres-Perez JF, Gonzalez-Santiago O. Home versus hospital mortality from cancer in Mexico (1999-2009). Am J Hosp Palliat Care. 2013;30(3):249-52.

9. Cicero-Oneto CE, Mata-Valderrama G, Valdez-Martínez E. La mortalidad en adolescentes con cáncer: características clinicoepidemiológicas de muerte y aspectos éticos emergentes [Mortality of young people with cancer: clinical-epidemiological characteristics of death and emerging ethical aspects]. Gac Med Mex. 2018;154(1):815. Spanish.

10. Leite AKF, Ribeiro KB. Older adults with cancer in the city of São Paulo: what factors determine the place of death? Rev Saude Publica. 2018;52:66.

11. Marcucci FCI, Cabrera MAS, Rosenberg JP, Yates P. Tendências nos locais de óbito no Brasil e análise dos fatores associados em idosos de 2002 a 2013 [Trends in place of death in Brazil and analysis of associated factors in elderly populations from 2002 to 2013]. Geriatr Gerontol Aging (Impr). 2017;11(1):10-7. Portuguese.

12. Alonso FT, Nazzal C, Alvarado ME. Mortality from ischemic heart disease in Chile: who, how many, and where. Rev Panam Salud Publica. 2010;28(5):319-25.

13. Leiva HH, León KF. Cobertura de la atención de la enfermedad que causa la muerte y lugar de ocurrencia del deceso, en Chile y la sexta región, 1990-2003 [Medical coverage of the disease that causes death and place of death in the sixth region of Chile from 1990-2003]. Rev Med Chil. 2007;135(8):1025-33. Spanish.

14. Suthar AB, Khalifa A, Yin S, Wenz K, Ma Fat D, Mills SL, et al. Evaluation of approaches to strengthen civil registration and vital statistics systems: a systematic review and synthesis of policies in 25 countries. PLOS Med. 2019;16(9):e1002929.

15. World Health Organization. Improving mortality statistics through civil registration and vital statistics systems: strategies for country and partner support. Geneva: World Health Organization; 2014. https://www.who.int/healthinfo/civil_registration/CRVS_MortalityStats_Guidance_Nov2014.pdf

16. Mills S, Lee JK, Rassekh BM. A multisectoral institutional arrangements approach to integrating civil registration, vital statistics, and identity management systems. J Health Popul Nutr. 2019;38(Suppl 1):19.

17. Cohen J, Bilsen J, Miccinesi G, Löfmark R, Addington-Hall J, Kaasa S, et al. Using death certificate data to study place of death in 9 European countries: opportunities and weaknesses. BMC Public Health. 2007;7:283.
18. Mathers CD, Ma Fat D, Inoue M, Rao C, Lopez AD. Counting the dead and what they died from: an assessment of the global status of cause of death data. Bull World Health Organ. 2005;83: 171-77.

19. Mikkelsen L, Phillips DE, AbouZahr C, Setel PW, De Savigny D, Lozano R, et al. A global assessment of civil registration and vital statistics systems: monitoring data quality and progress. Lancet. 2015;386:1395-406.

20. Phillips DE, Lozano R, Naghavi M, Atkinson C, Gonzalez-Medina D, Mikkelsen L, et al. A composite metric for assessing data on mortality and causes of death: the vital statistics performance index. Popul Health Metr. 2014;12(1):14.

21. Health Metrics Network, World Health Organization. Assessing the national health information system: an assessment tool, version 4.00. Geneva: World Health Organization; 2008. https:/ /apps.who. int/iris/handle/10665/43932

22. Lee JK, Jang SN. Place of death and associated gender difference in Korea 2006-2014: evidence from exit interviews of the Korean Longitudinal Study of Ageing. Arch Gerontol Geriatr. 2018;78:196-202.

23. Neergaard MA, Brunoe AH, Skorstengaard MH, Nielsen MK. What socio-economic factors determine place of death for people with life-limiting illness? A systematic review and appraisal of methodological rigour. Palliat Med. 2019;33(8):900-25.

24. Pan American Health Organization, World Health Organization. Core indicators 2019: health trends in the Americas. Washington (DC); 2019. https://iris.paho.org/handle/10665.2/51542

25. Departamento de Estadísticas e Información de Salud [Department of Statistics and Health information] (DEIS) [Internet]. Datos abiertos [Open data] [cited 2019 June 23]. Available from: https://deis. minsal.cl/\#datosabiertos.

26. Instituto Nacional de Estadística y Censos [National Institute of Statistics and Census] (INEC) [Internet]. Nacimientos y defunciones 2019 [Births and deaths 2019]. Quito: INEC; 2019 [cited 2019 June 29]. Available from: https://www.ecuadorencifras.gob.ec/ nacimientos_y_defunciones/.

27. Departamento Administrativo Nacional de Estadística [National Administrative Department of Statistics] (DANE) [Internet]. Defunciones no fetales 2017 [Non-fetal deaths 2017]. Bogotá: DANE; 2017 [cited 2019 July 3]. Available from: https://www. dane.gov.co/index.php/estadisticas-por-tema/salud/nacimientos-y-defunciones / defunciones-no-fetales / defunciones-no -fetales-2017.

28. Instituto Nacional de Estadística y Geografía [National Institute of Statistics and Geography] (INEGI) [Internet]. Mortalidad [Mortality]. Aguascalientes: INEGI; 2017 [cited 2019 June 23]. Available from: https:/ / www.inegi.org.mx/programas/mortalidad/default. html\#Datos_abiertos.

29. Archivo Nacional de Datos [Nacional Data Archive] (ANDA) [Internet]. Colombia - Estadísticas Vitales - EEVV - 2017-2018 [Colombia - vital statistics - 2017-2018] [cited 2019 July 12]. Available from: http://microdatos.dane.gov.co/index.php/catalog/652/ get_microdata.

30. Instituto Nacional de Estadística y Censos [National Institute of Statistics and Census] (INEC) [Internet]. Costa Rica: Total de defunciones 2014-2016, defunciones ocurridas e inscritas en el país en los años 2014, 2015 y 2016 [Costa Rica: Total number of deaths 2014-2016, deaths occurred and registered in the country in the years 2014, 2015 and 2016]. San José: INEC; 2019 [cited 2019 July 6]. Available from: http://sistemas.inec.cr/pad5/index.php/ catalog/266.

31. Peralta A, Benach J, Borrell C, Espinel-Flores V, Cash-Gibson L, Queiroz BL, et al. Evaluation of the mortality registry in Ecuador (2001-2013) - social and geographical inequalities in completeness and quality. Popul Health Metr. 2019;17(1):3.

32. Pan American Health Organization. Plan of action for the strengthening of vital statistics 2017-2022. Washington (DC): Pan American Health Organization; 2017. https://iris.paho.org/ handle/10665.2/34445 
33. Lopez AD, AbouZahr C, Shibuya K, Gollogly L. Keeping count: births, deaths, and causes of death. Lancet. 2007;370:1744-6.

34. Shibuya K, Gilmour S. Civil registration as a means to promote human security. Lancet. 2015;386:e14-5.

35. Mills S, Abouzahr C, Kim J, Rassekh BM, Sarpong D. Civil registration and vital statistics (CRVS) for monitoring the Sustainable Development Goals (SDGs). Washington (DC): World Bank; 2017.

36. World Bank. DataBank: world development indicators 2020 [Internet]. Washington (DC): World Bank [cited 2021 June 7].
Available from: https://databank.worldbank.org/source/world -development-indicators\#advancedDownloadOptions

Manuscript submitted 15 March 2021. Revised version accepted for publication on 14 July 2021.

\section{Factibilidad del uso de los certificados de defunción para estudiar el lugar de defunción en América Latina}

RESUMEN Objetivo. En este artículo se evalúa la disponibilidad y la calidad de los datos del certificado de defunción en América Latina y la factibilidad de emplear estos datos para estudiar el lugar de defunción y factores asociados.

Métodos. En este estudio comparativo, se recogieron ejemplos de certificados oficiales de defunción actuales y archivos digitales de datos que contenían información acerca de todas las defunciones que ocurrieron durante un año en 19 países latinoamericanos. Se recopilaron datos desde junio del 2019 hasta mayo del 2020. Se estudiaron los registros del lugar de la muerte y las variables asociadas. Los criterios para determinar la calidad de los datos fueron la exhaustividad, el número de causas de muerte mal definidas y la presentación oportuna de la información.

Resultados. Los 19 países proporcionaron copias de los certificados oficiales de defunción actuales; en 18 de estos se registraba el lugar de la muerte. En todos los países fue posible distinguir entre hospital u otra institución de atención de salud, el hogar y otros. Se obtuvieron los archivos de datos digitales con los datos del certificado de defunción de 12 países y una región. Tres países tenían datos considerados de buena calidad y siete tenían datos considerados de calidad media. En los archivos de datos se incluyeron categorías para lugar de defunción y la mayoría de los factores predeterminados posiblemente asociados con el lugar de defunción.

Conclusiones. La calidad de los conjuntos de datos se calificó de media a buena en 10 países. En consecuencia, es factible realizar un estudio internacional comparativo sobre el lugar de defunción y los factores asociados en América Latina con los datos del certificado de defunción.

Palabras clave Certificado de defunción; estudio comparativo; América Latina. 


\section{Viabilidade do uso de declarações de óbito para estudo do local do óbito na América Latina}

RESUMO

Objetivo. Este estudo avalia a disponibilidade e a qualidade dos dados das declarações de óbito na América Latina e a viabilidade de usar esses dados para estudar o local do óbito e fatores associados.

Métodos. Neste estudo comparativo, coletamos exemplos de declarações de óbito oficiais atuais e arquivos de dados digitais contendo informações sobre todos os óbitos que ocorreram durante 1 ano em 19 países latino-americanos. Os dados foram coletados no período de junho de 2019 a maio de 2020. Foram estudados os registros do local do óbito e variáveis associadas. Os critérios de qualidade dos dados foram preenchimento completo, número de causas mal definidas de morte e oportunidade.

Resultados. Todos os 19 países forneceram cópias das declarações de óbito oficiais atuais, e 18 deles registraram o local do óbito. Foi possível distinguir em todos os países entre hospital ou outra instituição de saúde, lar ou outro local. Arquivos de dados digitais com os dados das declarações de óbito foram disponibilizados por 12 países e 1 região. Três países tiveram dados considerados de alta qualidade, e sete tiveram dados considerados de qualidade média. As categorias de local do óbito e a maioria dos fatores predeterminados possivelmente associados ao local do óbito foram incluídos nos arquivos de dados.

Conclusões. A qualidade dos conjuntos de dados foi classificada como média a alta em 10 países. Portanto, os dados de declarações de óbito possibilitam a realização de um estudo comparativo internacional sobre local do óbito e fatores associados na América Latina.

Palavras-chave Atestado de óbito; estudo comparativo; América Latina. 